\title{
Beyond neutrality: adding habitat filtering to neutral models
}

\author{
Wasana Abeysinghe ${ }^{*}$ and Ruwan Punchi-Manage*
}

\begin{abstract}
Background: Understanding the processes that structure species is one of the primary focuses in community ecology. Hubbell's neutral model shows stochastic processes alone can describe the two macro-ecological patterns, species richness and species-area relationship, of the community. Although Hubbell's neutral model can explain the macro-ecological patterns of the species at large scales, it paid less attention to construct the spatial structure of the community. Previous studies suggest that such spatial structures are mostly due to habitat filtering processes work at the intermediate spatial scales. Therefore, Hubbell's neutral model does not explain the full picture of the community structuring due to its fully stochastic nature.

Results: In this study, we proposed a two-schema model that has the habitat filtering component and the stochastic component to construct the species assemblages seen in the community level. The proposed model uses one additional parameter (i.e. number of individuals in habitat) in addition to Hubbell's three-parameter neutral model (i.e. fundamental bio-diversity number $(\theta)$, dispersal limitation $(m)$ and speciation $(v)$ ). The proposed model works at two spatial scales: habitat filtering at the intermediate scales and stochastic processes at the large and very small spatial scales. The model coupled the local community dynamics with the meta-community dynamics. The local community has a fixed area with carrying capacity that is proportional to the local community size. The number of habitats in the proposed model can vary. Individuals are placed into habitats with probabilities according to the habitat suitability. Species richness and species composition in each habitat were calculated. The model is fitted for different $\theta$ values, $m$ values, and a different number of habitats.

Conclusions: We assume that habitat filtering plays an important role together with stochastic processes to structure species in forests. Therefore, the proposed model with only four parameters can explain a large proportion of the species structuring of the communities. We found that more species can be maintained in a heterogeneous environment than a uniform environment. Therefore, habitat conservation is highly important for maintaining species diversity in forest communities.
\end{abstract}

Keywords: Neutral theory, Habitat models, Fundamental bio-diversity number, Immigration, Local community

\section{Background}

All species compete for a common set of resources, such as water, nutrient and space. The competitive exclusion principle emphasises, in long run, two-species cannot coexist if they use a common set of resources (Gauss, 1934). Hence, the competitive exclusion principle states that, in the long run, one species becomes dominant by winning the full

\footnotetext{
* Correspondence: wasanaa93@gmail.com; sarangaamila@gmail.com Department of Statistics and Computer Science, Faculty of Science, University of Peradeniya, Peradeniya 20400, Sri Lanka
}

space while all the other species go extinct (Gauss, 1934). However, the coexistence of thousands in of species in tropical forests challenges this theory. Although majority of species, in tropical forests, are rare or singletons, their survival increases by habitat filtering, negative density dependence and dispersal syndromes (Janzen 1970; Connell 1971; Harms et al. 2004; Gunatilleke et al. 2006; Seidler and Plotkin Chuyong et al. 2011; Liu et al. 2018). Habitat filtering hypothesis states that habitat suitability affects birth rates, death rates and speciation rates of species. This theory also
Springer Open

(c) The Author(s). 2020 Open Access This article is licensed under a Creative Commons Attribution 4.0 International License, which permits use, sharing, adaptation, distribution and reproduction in any medium or format, as long as you give appropriate credit to the original author(s) and the source, provide a link to the Creative Commons licence, and indicate if changes were made. The images or other third party material in this article are included in the article's Creative Commons licence, unless indicated otherwise in a credit line to the material. If material is not included in the article's Creative Commons licence and your intended use is not permitted by statutory regulation or exceeds the permitted use, you will need to obtain permission directly from the copyright holder. To view a copy of this licence, visit http://creativecommons.org/licenses/by/4.0/. 
assumes such species-habitat associations maintain species richness by delaying the species mono-dominance.

In contrast, Hubbell's neutral theory, a fully stochastic process, proposed species are ecologically equivalent. Therefore, per capita birth rates, death rates and speciation rates are the same for all the species (Hubbell 1997; Hubbell 2001). The neutral theory suggests species richness in a local community can be maintained by the stochastic birth-death process at the local community and immigration of species from the meta-community. In the meta-community, speciation introduces new species (Hubbell 1997; Hubbell 2001). This theory successfully predicts two macro-ecological patterns (i.e. species abundance distribution and species-area relationship) using three parameters (i.e. the fundamental biodiversity number, the immigration rate or the fundamental dispersal number and the speciation rates) (Hubbell 1997; Hubbell 2001; McGill 2003). This theory has great popularity among ecologist due to its simplicity (Rosindell et al. 2011, Rosindell et al. 2012). However, Hubbell's neutral model that placed individuals randomly does not incorporate the spatial arrangement of the species. Spatial patterns of the species hide large information that is highly important to understand the underlying processes on species structuring at different spatial scales (Hubbell 1979; He et al. 1996; $\mathrm{He}$ et al. 1997; Condit et al. 2000; Wiegand and Moloney 2004; Gunatilleke et al. 2006; Wiegand et al. 2007; Getzin et al. 2008; Wang et al. 2008; Wang et al. 2010; Wiegand et al. 2012).

Importance of habitats to explain the species coexistence is widely documented (Harms et al. 2004; Valencia et al. 2004; Gunatilleke et al. 2006; Lai et al. 2009; Wang et al. 2009, Zhang et al. 2012, 2013). For example, an addition of different habitat preferences for members of a species with different genotypes will enable alleles that facilitate survival in those habitats to be maintained as balanced polymorphisms in the population (Levene 1953, Barton 2010). In contrast, the importance of neural or stochastic processes to explain the diversity is extensively discussed. For example, Kimura (1983) suggests that "genetic drift" is a neutral process that can change the allele frequencies over time. Hubbell $(1997,2001)$ used a similar term called "ecological drift" to explain the macroecological patterns in diverse communities (see Leigh (2007) for the evolution of the neutral theory). Some authors suggest that species-habitat association and dispersal patterns (stochastic processes) together can play important roles for species structuring at the intermediate scales (Webb and Pert 2000; Harms et al. 2004; Valencia et al. 2004; Gunatilleke et al. 2006; Seidler and Plotkin 2006; Wang et al. 2009; Qi et al. 2011; Liu 2014; Guo et al. 2017; Liu et al. 2018). However, their stochastic processes differ from Hubbell's ecological drift or immigration of species from meta- communities. Some suggest that spatial pattern at small scales is due to pathogens and species interactions (Connell 1971; Wright 2002; Gilbert and Lechowicz 2004). Neutral theory suggests stochastic processes at small spatial scales cause species diversity to be unpredictable at small scales.

There are studies that quantify the relative importance of neutral and niche assembly processes to describe the species richness at different spatial scales (Tuomisto et al. 2003; Gilbert and Lechowicz 2004; Jones et al. 2008; Li et al. 2011; Lin et al. 2013; Shen et al. 2013; Lin et al. 2013; Baldeck et al. 2013; Wang et al. 2014; Van der Plas et al. 2015; Yu et al. 2016; Yang et al. 2016; Henkel et al. 2019). However, only few studies highlight the importance of a general mathematical framework to link the processes (e.g. Azaele 2015; Azaele et al. 2016; Matthews and Whittaker 2014; Munoz et al. 2014; Van der Plas et al. 2015).

Here, we asked how many species can be maintained by a neutral model to which one new level of complexity, i.e. space, has been added. For that, we proposed a two-stage model that used species-habitat association and Hubbell's stochastic processes (i.e. birth-death and dispersal limitation and speciation rates) to describe the species richness. We add habitat filtering into Hubbell's spatial explicit neutral model to capture ecological processes (i.e. stochasticity, species-habitat association and dispersal limitation) at different spatial scales. Our proposed model uses four parameters, where three parameters come from Hubbell's neutral model, to generate the species richness at a local community. Our model can generate species richness (and also species composition) for many numbers of habitats and different types of habitats (isolated habitats or connected habitats) by adding one additional parameter (we called this "number of individuals each in habitats").

\section{Methods \\ Habitat conservative neutral model}

We incorporate Hubbell et al. (2001), Etienne et al. (2005) and Munoz et al. (2007, 2014) to develop our model. We used two stage schemas to generate the regional species pool and the local community. First, we simulate the reference pool with labelling the species. Then immigrants from the regional pool were filtered according to its habitat preference under neutrality. In general, this newly proposed model can be used for the local community with any size with any number of habitats.

We have the following two steps in the model.

\section{Meta-community dynamics}

Meta-community size is very large $\left(J_{M}=10^{7}\right)$. Species diversity of the meta-community is driven by two parameters. Fundamental biodiversity number $\theta=40$ and 50 , 
and speciation rate $(v<<<<1)$. At the beginning, the number of species in the meta-community is assumed zero. The first individual in the meta-community has the species label $s=1$ and individual number $i=1$. The second individual of the meta-community can be an offspring of the first individual or new species. If it is an offspring of the previous species, it has the same species label $s=1$ and a new individual number $i=2$. If it is a new species, then it has a new species label $s=2$ and a new individual number $i=2$. The rate of new species coming into the regional pool (meta-community) depends on the relative species abundance of the meta-community. When individuals in the regional pool increase, the speciation rate is slowed down. This was incorporated into the model by generating a random number called $R 1=\frac{\theta}{\theta+i-1} . R 1$ is called the random number generator, where $\theta$ is the fundamental biodiversity number, a constant. When individuals in the regional pool increase, i.e. when $i$ increases, then $R 1$ decreases. If the generated random number is less than the $R 1$, then individual receives a new species label $(s=s+1)$. Otherwise, a species label is randomly assigned to the individual from the previous species (therefore, species label number depends on the relative species abundance of species in the regional pool at that time). Hence, each individual is tested for whether it is a new species or offspring from previous species.

\section{Local community dynamics}

Local community has $J$ number of individuals. The number of habitats $(h=1,2, \ldots)$ in the local community is pre-determined. One of the assumptions in the Hubbell (2001) neutral theory is that the local community is saturated. The number of individuals in each habitat is fixed $\left(J_{h}\right)$, and it is proportional to the area occupied by each habitat $\left(J_{h}=J \times \frac{\text { area of } h_{i}}{k}\right)$. It is assumed

$$
\sum_{h=1}^{k} \text { area of } h_{i}
$$

that in a community with a saturated number of individuals, the number of individuals $(J)$ in an area is proportional to the area sample $(A)$ (i. e. $J=\rho A$ ). Fundamental immigration number $\left(I_{0}\right)$ is defined by $I_{0}=\frac{m \times\left(J_{i}-1\right)}{(1-m)}$, where $m$ is the dispersal limitation $(0 \leq$ $m \leq 1)$. Dispersal limitation depends on the strength of local community couple with the metacommunity. If the local community is fully isolated, then $m=0$. We assumed that $m$ depends on the distance between habitat to the meta-community. Here we assumed that distance from habitat to metacommunity is the same for all the habitats. Therefore, $m$ is the same for all the habitats. Hence, the fundamental immigration number $\left(I_{0}\right)$ is proportional to the number of individuals in that habitat.

\section{Simulation of local community}

The first individual of the local community is randomly drawn from the regional pool (the probability of species $s$ in the local community is proportional to the relative species abundance of the regional pool), and it is placed on one of the randomly selected quadrate (quadrates were selected randomly without replacement). Species label is the same as the meta-community species label.

In the next step, another habitat is randomly chosen without replacement. If the habitat is empty, an individual is randomly drawn from the meta-community and received the same species label. If it is not an empty habitat, there are two possibilities. The second individual in the local community may come from the offspring of the already established species in the local community (if so, then it has the same species label) or species from the regional pool proportional to relative species abundance of the regional pool. However, species from the regional pool may be a new species or the same species of the regional pool.

Whether species is an offspring of the species in that habitat or species from regional species pool depends on the fundamental immigration number. We select a random number from a unit length, and if this random number is less than the $R 2=\frac{I_{0}[k]}{I_{0}[k]+j-1}$ replacement is from the regional species pool and otherwise, it is an offspring of the randomly drawn individual from the local community. When the local community grows, the rate of new species that comes into the local community decreases.

The above three steps (i.e. 3.5-3.7) were performed until the local community is saturated $(J=125,000$, i.e. all the habitats are completely occupied by the individuals).

\section{Results}

The new model describes the effect of habitat filtering and neutral components on species richness. First, we fixed two parameters and change the other parameter to understand the effects of each parameter on species richness. We used the same meta-community for all three scenarios.

\section{Effects of number of individuals in habitats on species richness of local communities}

We fixed the parameters $\theta$ and $I$ (see Table 1 ). Then we defined two habitats with different sizes. We assumed that the habitats are fully saturated and habitat preference is proportional to the habitat size. Therefore, in two habitats with equal sizes, their habitat preferences are equal to 0.5 . When individuals in the second habitat are two times greater than the individuals in the first habitat, habitat preferences for the first and second 
Table 1 Local species composition for fundamental immigration number $(I=100)$ and the fundamental biodiversity number $(\theta=$

\begin{tabular}{|c|c|c|c|c|c|c|c|}
\hline \multicolumn{2}{|c|}{ Number of individuals in habitat } & \multicolumn{2}{|c|}{ Habitat preference } & \multicolumn{2}{|c|}{ No. of individuals } & \multicolumn{2}{|c|}{ Species richness } \\
\hline Habitat $1\left(\boldsymbol{h}_{\mathbf{1}}\right)$ & Habitat $2\left(\boldsymbol{h}_{\mathbf{2}}\right)$ & Habitat 1 & Habitat 2 & Habitat 1 & Habitat 2 & Habitat 1 & Habitat 2 \\
\hline 25 & 25 & 0.500 & 0.500 & 25 & 25 & 21 & 18 \\
\hline 50 & 50 & 0.500 & 0.500 & 50 & 50 & 28 & 33 \\
\hline 75 & 75 & 0.500 & 0.500 & 75 & 75 & 39 & 42 \\
\hline 100 & 100 & 0.500 & 0.500 & 100 & 100 & 45 & 49 \\
\hline 300 & 300 & 0.500 & 0.500 & 300 & 300 & 55 & 63 \\
\hline 50 & 100 & 0.330 & 0.670 & 50 & 100 & 29 & 44 \\
\hline 25 & 125 & 0.167 & 0.833 & 25 & 125 & 24 & 51 \\
\hline 15 & 135 & 0.100 & 0.900 & 15 & 135 & 17 & 53 \\
\hline
\end{tabular}

habitats are $1 / 3$ and $2 / 3$, respectively. We observed species richness increases with the number of individuals in the habitat.

\section{Effects of fundamental biodiversity number $(\theta)$ on species richness of local communities}

We fixed the number of individuals in two habitats (i.e. $\left.h_{1}=50, h_{2}=100\right)$ and the fundamental immigration number (i.e. $I=100$ ) (see Table 2). Results show species richness increases in each habitat and the local community when fundamental biodiversity number $(\theta)$ increases.

\section{Effects of immigration parameter $(I)$ on the species richness of the local community}

Fundamental biodiversity number $(\theta=50)$ and the number of individuals in each habitat is fixed $\left(h_{1}=50, h_{2}=\right.$ 100) (see Table 3). Results show species richness increases in each habitat and the local community when fundamental immigration number $(I)$ increases.

Table 2 Simulated species richness for fixed meta-community size $\left(\theta=50, J_{M}=1000\right)$ and local community size $\left(J_{m}=150\right), I=$ $100, h_{1}=50, h_{2}=100$

\begin{tabular}{lll}
\hline $\boldsymbol{\Theta}$ & \multicolumn{2}{l}{ Species richness } \\
\cline { 2 - 3 } & Habitat 1 & Habitat 2 \\
\hline 0.001 & 1 & 1 \\
0.100 & 2 & 2 \\
1.000 & 4 & 5 \\
10.000 & 19 & 22 \\
50.000 & 31 & 37 \\
100.000 & 36 & 50 \\
500.000 & 41 & 67 \\
\hline
\end{tabular}

\section{Effects of number of habitats on the species richness of} the local community

Figure 1 shows species rank abundance in the local community when the neutral model is used. Neutral models were fitted for five different sizes of local communities.

Figures 2, 3 and 4 show species rank abundance in the local community when the habitat-based neutral model is used. Habitat-based neutral models were fitted for five different sizes of local communities (Figs. 5 and 6). Figure 2 shows local community species rank abundance when two equally sized habitats are present. Figure 3 shows community species rank abundance when four equally sized habitats are present in the local community. Figure 4 shows local community species rank abundance when five equally sized habitats are present. All these scenarios $\theta$ and I were fixed.

We noticed that when local community size increases, both species richness and number of rare species in the community are increased. This observation is very clear for large communities. For example, adding one additional habitat can increase the species richness from 120 to 140 (see Fig. 3 with Fig. 4). When four habitats are present, almost 35 species are singletons (Fig. 7).

Table 3 Simulated species richness values for fixed metacommunity size $\left(\theta=50, J_{M}=1000\right)$ and local community size $\left(J_{m}=150\right), h_{1}=50, h_{2}=100$

\begin{tabular}{lll}
\hline $\boldsymbol{I}$ & \multicolumn{2}{l}{ Species richness } \\
\cline { 2 - 3 } & Habitat 1 & Habitat 2 \\
\hline 1 & 4 & 4 \\
20 & 19 & 23 \\
50 & 25 & 37 \\
80 & 30 & 36 \\
100 & 29 & 45 \\
150 & 27 & 47 \\
\hline
\end{tabular}




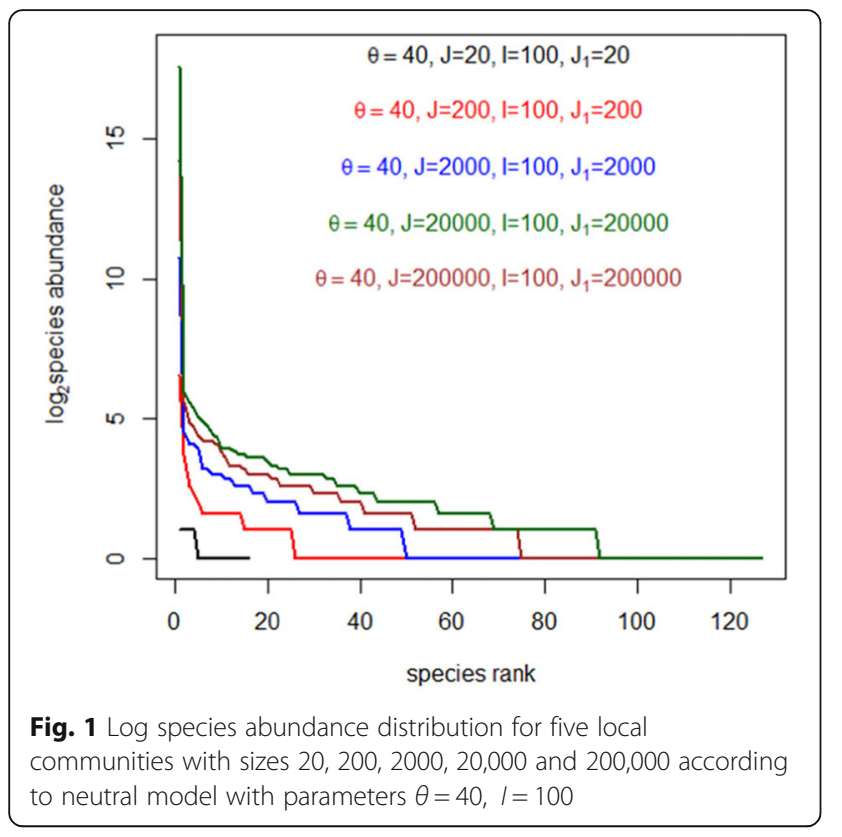

When five habitats are present, almost 45 species are singletons (Fig. 8).

Habitats decrease the abundance of common species in the local community (Figs.1, 2, 3 and 4). When local community size is fixed (e.g. for 200,000 individuals) dominant species in the neutral model, the two habitat-based neutral models, four habitat-based neutral models and five habitat-based neutral models show 199,238, 99,716, 50,254 and 40,162 individuals, respectively (Figs.1, 2, 3 and 4).

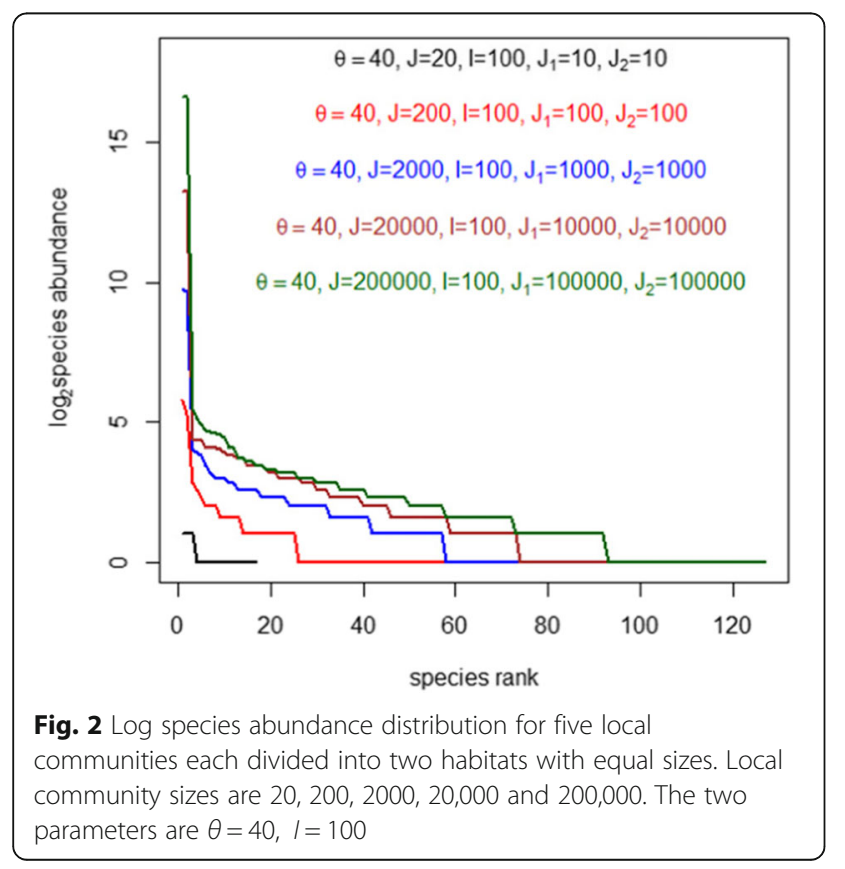

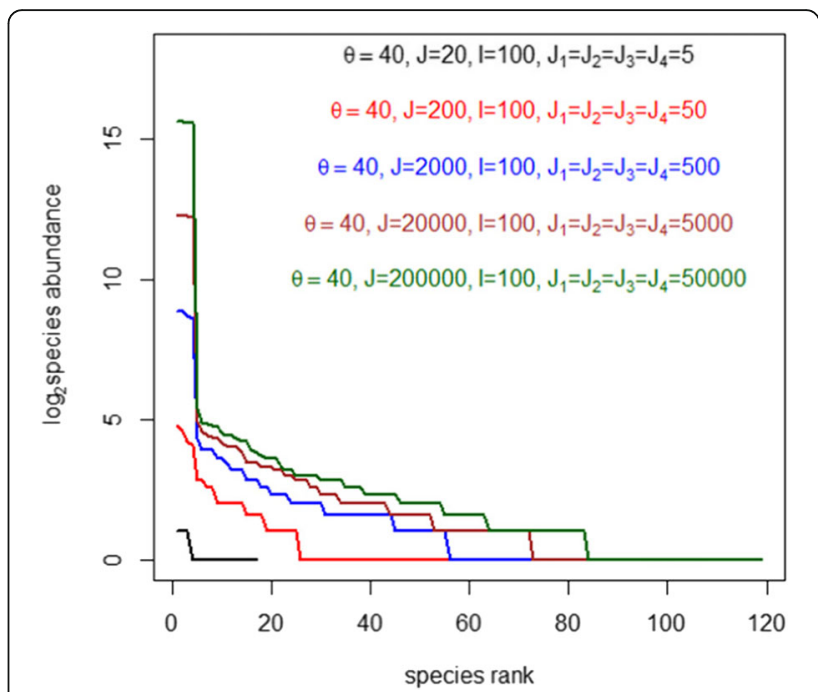

Fig. 3 Log species abundance distribution for five local communities each divided into four habitats with equal sizes. Local community sizes are 20, 200, 2000, 20,000 and 200,000. Two parameters are $\theta=40, I=100$.

\section{Discussion}

Ecology has a rich history on describing species richness and species abundance distributions using simple models (Fisher 1943, Preston 1948, 1962 MacArthur 1957, Sugihara 1980, Tokeshi 1990; Hubbell 2001). Such parsimonious models are called "Occam's razors" in Ecology (Sober 1990; Baker 2007). These simple models are broadly categorised into purely statistical models, neutral models, and niche-partitioning models (Ferreira et al. 2008; Marquet et al. 2014). However, almost all of these models fail to fully

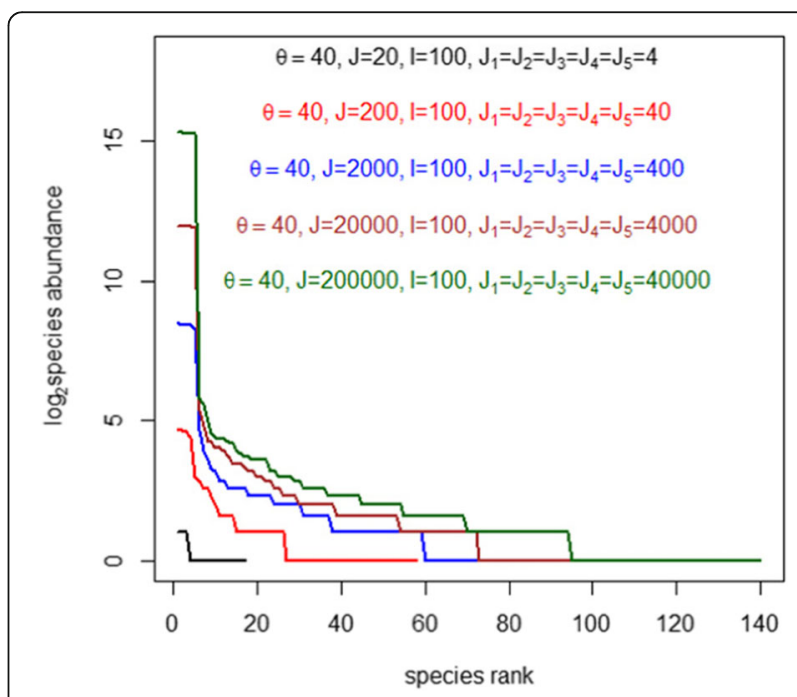

Fig. 4 Log species abundance distribution for five local communities each divided into five habitats with equal sizes. Local community sizes are 20,200,2000,20,000 and 200,000. The two parameters are $\theta=40, I=100$ 


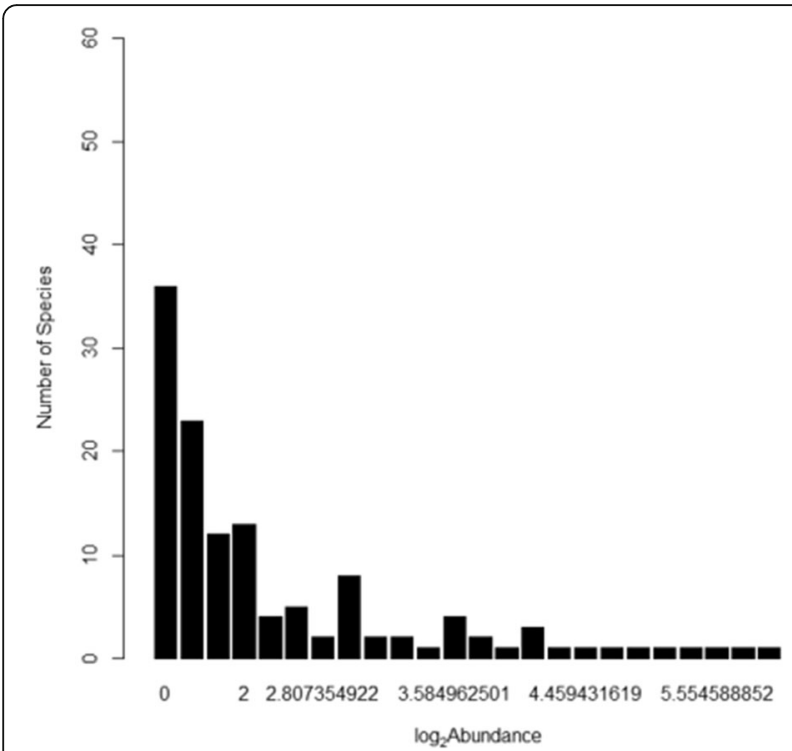

Fig. 5 Number of species vs. log species abundance for local communities with single habitat size. Local community size is 200,000 with parameters $\theta=40, I=100$. This model is equivalent to neutral model

describe the species abundance distribution especially its long tail rare species distribution (Hubbell 2001). Some models (e.g. pure statistical models) lack biological meaning.

Hubbell's developed three parameters fully stochastic model that can describe the long tail rare species abundance distribution in the tropical forests (Hubbell 2001). One of the core assumptions of the neutral theory is that all the species are equivalent with respect to their per

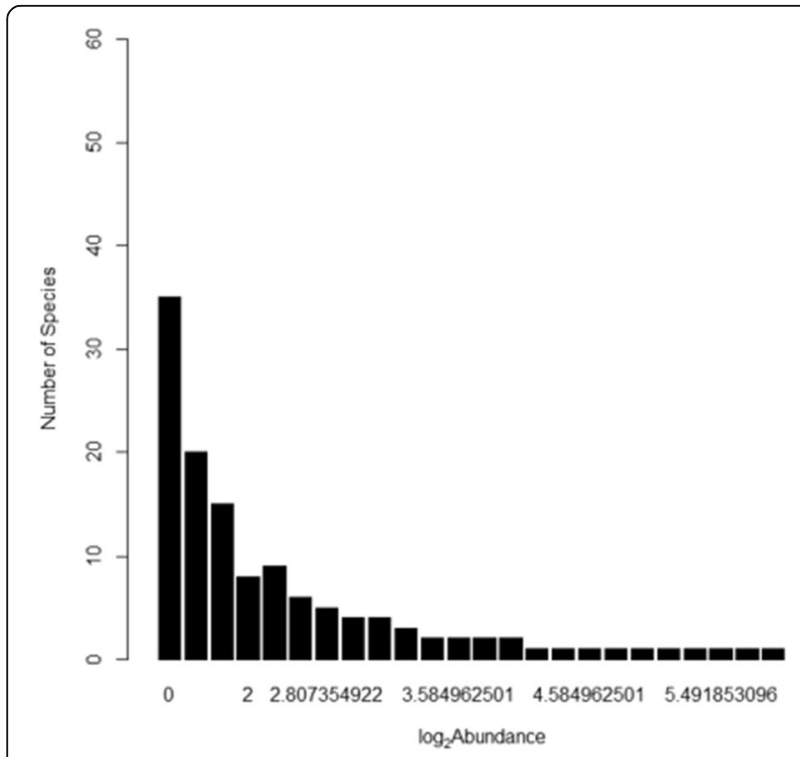

Fig. 6 Number of species vs. log species abundance for local communities with two equal-sized habitats. Local community size is 200,000 and the two parameters are $\theta=40, I=100$

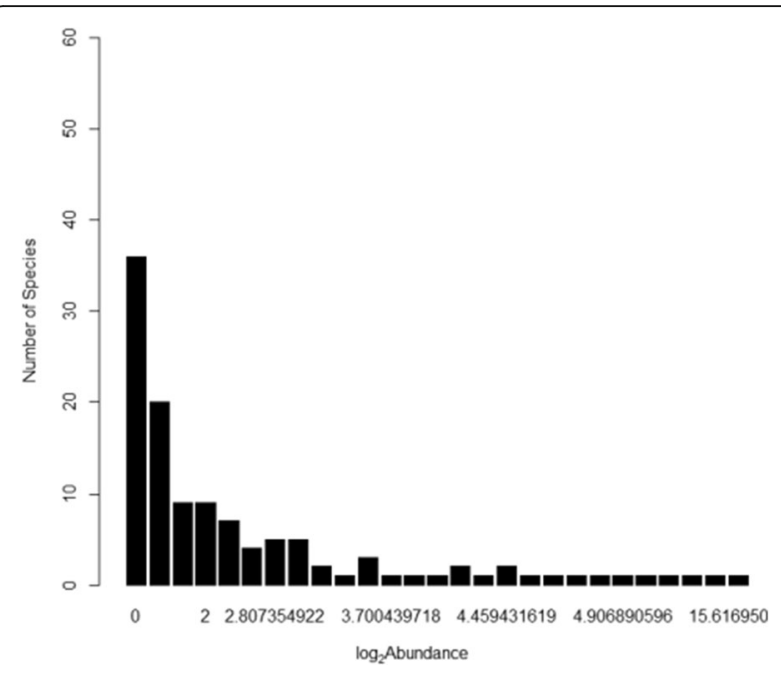

Fig. 7 Number of species vs. log species abundance for the local community divided into four equal-sized habitats. Local community size is 200,000 and the two parameters are $\theta=40, I=100$

capita birth rates, death rates and speciation rates (Hubbell 2001). Although many argued that the ecological equivalence of species is not realistic, this reality simplification assumption helps to form a null model for ecologist. Hence, the falsifiability of this assumption left more lights for ecologist and the assumption of "ecological equivalence" cannot be regarded as a weakness of the neutral theory (Alonso et al. 2006).

Some authors relaxed this "ecological equivalence" assumption so that they could study the species coexistence in more general (Zhou and Zhang 2008; He et al.

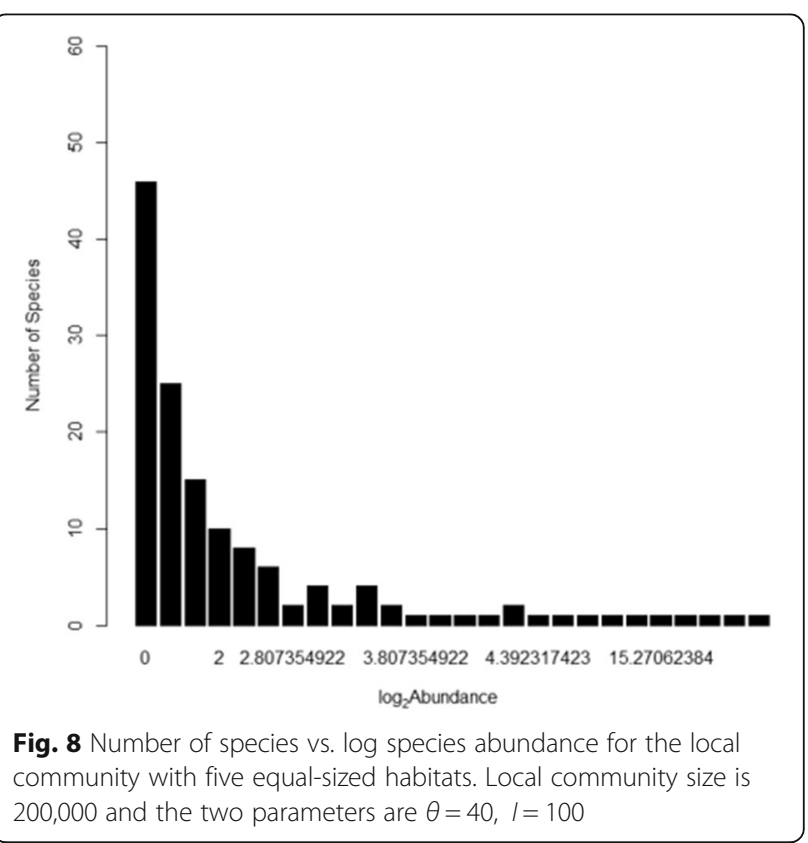


2012, Zhang et al. 2012, Zechen et al. 2012). For example, Zhou and Zhang (2008) show that subtle changes to species fecundity drastically reduced the species richness and changes to species abundance distribution. They argued that even strong dispersal limitations cannot compensate for the subtle changes to species fecundity to maintain the species richness. In a similar direction, Zechen et al. (2012) show that, to observe neutral-like species abundance, distribution patterns under slightly asymmetric competition need severe dispersal and recruitment limitations. Therefore, dispersal and recruitment limitations are not sufficient to compensate for the difference in species fitness (Zechen et al. 2012). Hence, more ingredients need to build a unified theory. However, He et al. (2012) and Zhang et al. (2012) show the assumption of "ecological equivalence" when species birth rates and death rates are tradeoff. They show that "generalised neutral models" (i.e. species birth-death rates are tradeoff) yield the same macro-ecological patterns as the neutral model. According to our view, He et al. (2012) and Zhang et al. (2012) define ecological equivalence of species at fitness level.

The second assumption of the neutral theory is that the community undergoes a zero-sum game (Hubbell 2001). Volkov et al. 2003; Etinne et al. 2007 found that relaxing the zero-sum assumption does not affect the species abundance distribution pattern. However, we used the "zerosum game" to relax the ecological equivalence from the local community to habitat. According to the zero-sum game (described by Hubbell 2001), the local community is saturated. Therefore we can assume that at some point, all the habitats are fully occupied by individuals. Hubbell (2001) describes for saturated communities, community size is proportional to the area of the local community. Therefore, we can assume that, in the long run, habitat preference is proportional to the number of individuals in the habitat (habitat size).

Therefore, it is very important to consider the number of individuals in each habitat as a parameter to reconcile the neutral theory with the habitat associations. We think that adding this parameter into the neutral theory increases our understanding of the underlying processes that shape the ecological communities without disturbing the degrees of freedom of the neutral models. The additional parameter allows us to place species into habitats with different probabilities. Hence, it allows us to relax one of the core assumptions in the Hubbell's neutral model: "species are equivalent". The neutral theory allows total freedom for species to move in the local community. However, our model relaxed this assumption and restricted species range so that off-springs can move only in parent habitat. However, our model still allows species to move within the habitat. Therefore, the independence of species is achieved at the habitat level.
This additional parameter also helps to construct the spatial arrangement of the local community. The neutral theory does not incorporate the exact spatial arrangement of the species in local communities (Armesto et al. 1986; Condit et al. 2000; Wiegand et al. 2012). We agree that such exact spatial arrangements are not important for the neutral theory to describe the aggregated statistics such as macro-ecological patterns (i.e. species richness and species abundance) at the large spatial scales. However, one major criticism is that a large amount of information loss in neutral models is due to aggregated statistics. Therefore, the neutral theory cannot explain the species composition. In this regard information on the spatial arrangement of species is very important to increase the understanding of the underlying processes in ecological communities at different spatial scales.

Our model shows the habitat increases the number of rare species in the community. Hubbell (2013) found that almost all of the tree diversity comes from $0.1 \%$ to $4.1 \%$ of individuals in tropical forests, which are rare species. Tropical forests provide shelter for thousands of rare species, and most of them are singletons. Therefore, conservation of habitats is uppermost important to maintain the species diversity of these tropical forests to slow the extinction of rare species and increase its numbers. Our results indicate species abundance distribution pattern becomes flat and much wider when the number of habitats increases. On the other hand, this model reduces the abundance of dominance species, which allows other species to increase their numbers and delay the competitive exclusion.

Our model has limitations. First, we defined habitat as spatial regions. Further, we assumed that the competition for space is equal for each and every individual (i.e. similar to Hubbell's neutral model). Although space is one of the important and limited resources that all the species compete for, there are several other variables one can incorporate to define habitats more broadly. This may include an abundance of pollinators, predators, prey and diseases. Such density-dependent processes may act on species richness and diversity at different spatial scales. For example, species-specific pollinators can increase the abundance of most abundance species by decreasing the abundance of rare species. On the other hand predators (e.g. herbivores), diseases and pathogens can help to decrease the abundance of dominant species, thus allowing rare species to increase its numbers. Thus, incorporating such variables bring our model much closer to reality. However, adding more variables into a model increases the model complexity. As we mentioned before, ecology has a rich history of the parsimonious model to explain the complex natural phenomena and our idea was to add space into Hubbell's neutral model to build a simple model. 
Second, we defined habitat as a space where a set of species coexists together. This is a definition we adapted from studies done in large forest plots such as BCI, Sinharaja, etc. (Harms et al. 2004, Gunatilleke et al. 2006). We accept that defining habitat for each species to allow the opportunity to test our model to its logical extremes and estimate the range of possible effects better. Especially, such constraint allows species-species (interspecific) interaction to become zero. However, in the beginning, we assumed that the local community is saturated and the number of individuals in a local community is proportional to its area. Thus, allowing habitat for each species causes habitat size to be proportional to the number of individuals. In other words, we can see that habitat sizes in a local community follow the exact same pattern as relative species abundance distribution. On the other hand, we doubt that adding habitat for each species might cause habitats to be completely overlapped with the niches due to zero interaction among species.

\section{Conclusions}

Our model suggests that "the number of individuals in habitats" can enhance our understanding on species assemblages of the local communities. Our findings support the idea that the "range sizes" are different for species in tropical forests. Therefore, rare species may be restricted to a certain habitat and has a greater risk of extinction (Hubbell 2013).

We conclude that the new model with only four parameters, theta $(\theta)$, immigration parameter $(I)$, speciation, and the number of individuals in the habitats, helps to understand the species richness in habitats. Changes to model parameters can construct species richness of any local community with different numbers of habitats.

\section{Supplementary information}

Supplementary information accompanies this paper at https://doi.org/10. 1186/s13717-020-00228-7.

Additional file 1. Supplementary information

\section{Acknowledgements}

We thank the Editor and two anonymous reviewers for carefully reading our manuscript and providing very useful comments and suggestions.

\section{Authors' contributions}

WA and RP developed the model, found the results and wrote the paper. The authors read and approved the final manuscript.

\section{Funding}

The authors received no funding.

Ethics approval and consent to participate Not applicable.

\section{Consent for publication}

Not applicable.

\section{Competing interests}

The authors declare that they have no competing interests.

Received: 20 November 2019 Accepted: 7 April 2020

Published online: 29 May 2020

\section{References}

Alonso D, Etienne RS, McKane AJ (2006) The merits of neutral theory. Trends Ecol Evol 21(8):451-457

Azaele S, Maritan A, Cornell SJ, Suweis S, Banavar JR, Gabriel D, Kunin WE (2015) Towards a unified descriptive theory for spatial ecology: predicting biodiversity patterns across spatial scales. Meth Ecol Evol 6(3):324-332

Azaele S, Suweis S, Grilli J, Volkov I, CBanavar JR, Maritan A (2016) Statistical mechanics of ecological systems: neutral theory and beyond. Rev Mod Phys 88:035003

Barton NH (2010) What role does natural selection play in speciation? Phil Trans R Soc B 365:1825-1840. https://doi.org/10.1098/rstb.2010.0001

Chuyong GB, Kenfack D, Harms KE, Thomas DW, Condit R, Comita LS (2011) Habitat specificity and diversity of tree species in an African wet tropical forest. Plant Ecol 212(8):1363-1374

Condit R, Ashton PS, Baker P, Bunyavejchewin S, Gunatilleke S, Gunatilleke N, Hubbell SP, Foster RB, Itoh A, Lafrankie JV, Lee HS, Elizabeth L, Manokaran N, Sukumar R, Yamakura T (2000) Spatial patterns in the distribution of tropical tree species. Science 288:1414-1417

Connell JH (1971) On the role of natural enemies in preventing competitive exclusion in some marine animals and in rain forest trees. In: Boer PJD, Gradwell GR (eds) Dynamics of populations. Centre for Agricultural Publication and Documentation, Wageningen, Netherlands, pp 298-312

Etienne RS (2005) A new sampling formula for neutral biodiversity. Ecol Lett 8 : $253-260$

Ferreira FC, Petrere-Jr M (2008) Comments about some species abundance patterns: classic, neutral, and niche partitioning models. Braz I Biol 68:10031012 https://doi.org/https://doi.org/10.1590/S1519-69842008000500008

Fisher RA, Corbet AS, Williams CB (1943) The relation between the number of species and the number of individuals in a random sample of an animal population. J Anim Ecol 12:42-58

Gause GF (1934) The struggle for existence. Williams and Wilkins, Baltimore, MD

Getzin S, Wiegand T, Wiegand K, He F (2008) Heterogeneity influences spatial patterns and demographics in forest stands. J Ecol 96(4):807-820

Gilbert B, Lechowicz MJ (2004) Neutrality, niches, and dispersal in a temperate forest understory. Proc Natl Acad Sci USA 101(20):7651-7656

Gunatilleke CVS, Gunatilleke IAUN, Esufali S, Harms KE, Ashton PMS, Burslem DFRP, Ashton PS (2006) Species-habitat associations in a Sri Lankan dipterocarp forest. J Trop Ecol 22:371-384

Guo Y, Wang B, Mallik AU, Huang F, Xiang W, Ding T, Wen S, Lu S, Li D, He Y, Li $X$ (2017) Topographic species-habitat associations of tree species in a heterogeneous tropical karst seasonal rain forest, China. J Plant Ecol 10:450460 https://doi.org/https://doi.org/10.1093/jpe/rtw057

Harms KE, Condit R, Hubbell SP, Foster RB (2004) Habitat associations of trees and shrubs in a 50-ha neotropical forest plot. J Ecol 89(6):947-959

He F, Zhang D, Lin K (2012) Coexistence of nearly neutral species. J Plant Ecol 5(1):72-81

He FL, Legendre P, LaFrankie JV (1996) Spatial pattern of diversity in a tropical rain forest in Malaysia. J Biogeogr 23(1):57-74

He FL, Legendre P, LaFrankie JV (1997) Distribution patterns of tree species in a Malaysian tropical rain forest. J Veg Sci 8(1):105-114

Hubbell SP (1979) Tree dispersion, abundance, and diversity in a tropical dry forest. Science 203(4387):1299-1309

Hubbell SP (1997) A unified theory of biogeography and relative species abundance and its application to tropical rain forests and coral reefs. Coral Reefs 16:S9-S21

Hubbell SP (2001) The unified neutral theory of biodiversity and biogeography Princeton University press. Princeton, NJ

Janzen DH (1970) Herbivores and the number of tree species in tropical forests. Am Nat 104(940):501-528

Kimura M (1983) The neutral theory of molecular evolution. Cambridge University Press, Cambridge

Lai J, Mi X, Ren H, Ma K (2009) Species-habitat associations change in a subtropical forest of China. J Veg Sci 20(3):415-423

Leigh E (2007) Neutral theory: a historical perspective. J Evol Biol 20:2075-2091 
Levene $H$ (1953) Genetic equilibrium when more than one niche is available. Am Nat 87:331-333

Li Q, Yang X, Soininen J, Chu C, Zhang J, Yu K, Wang G (2011) Relative importance of spatial processes and environmental factors in shaping alpine meadow communities. J Plant Ecol 4(4):249-258

Lin G, Stralberg D, Gong G, Huang Z, Ye W, Wu L (2013) Separating the effects of environment and space on tree species distribution: from population to community. PLoS One 8(2):e56171

Liu J, Yunhong T, Slik JWF (2014) Topography related habitat associations of tree species traits, composition and diversity in a Chinese tropical forest. For Ecol Manag 330:75-81

Liu Q, Bi L, Song G, Wang Q, Jin G (2018) Species-habitat associations in an oldgrowth temperate forest in northeastern China. BMC Ecol 18(1):20. https:// doi.org/10.1186/s12898-018-0177-9

MacArthur RH (1957) On the relative abundance of bird species. Proc Natl Acad Sci U S A 43(3):293-295

Marquet PA, Allen AP, Brown JH, Dunne JA, Enquist B, Gillooly JF, Gowaty PA, Green JL, Harte J, Hubbell SP, O'Dwyer J, Okie JG, Ostling A, Ritchie M, Storch D, West GB (2014) On theory in ecology. BioScience 64(8):701-710

Matthews TJ, Whittaker RJ (2014) Neutral theory and the species abundance distribution: recent developments and prospects for unifying niche and neutral perspectives. Ecol Evol 4(11):2263-2277

McGill BJ (2003) A test of the unified neutral theory of biodiversity. Nature 422: $881-885$

Munoz F, Couteron P, Ramesh BR, Etienne R (2007) Estimating parameters of neutral communities: from one single large to several small samples. Ecology 88(10):2482-2488

Munoz F, Ramesh BR, Couteron P (2014) How do habitat filtering and niche conservatism affect community composition at different taxonomic resolutions. Ecology 95(8):2179-2191

Preston FW (1948) The commonness and the rarity of species. Ecology 29(3):254283

Preston FW (1962) The canonical distribution of commonness and rarity. Ecology 43:185-215

Rosindell J, Hubbell SP, Etienne RS (2011) The unified neutral theory of biodiversity and biogeography at age ten. Trends Ecol Evol 26(7):340-348

Seidler TG, Plotkin JB (2006) Seed dispersal and spatial pattern in tropical trees. PLoS Biol 4(11):2132-2137

Shen G, He F, Waagepetersen R, Sun I, Hao Z, Chen ZS, Yu M (2013) Quantifying effects of habitat heterogeneity and other clustering processes on spatial distributions of tree species. Ecology 94(11):2436-2443

Sober E (1990) Explanation in biology: Let's razor Ockham's razor. R Inst Philos Suppl 27:73-93

Sugihara G (1980) Minimal community structure: an explanation of species abundance patterns. Am Nat 116(6):770-787

Tokeshi M (1990) Niche apportionment or random assortment: species abundance patterns revisited. J Anim Ecol 59(3):1129-1146

Tuomisto H, Ruokolainen K, Yli-Halla M (2003) Dispersal, environment, and floristic variation of Western Amazonian forests. Science 299(5604):241-244

Van der Plas F, Janzen T, Ordonez A, Fokkema, W, \& Reinders J, \& Etienne R, \& Olff $H$ (2015). A new modeling approach estimates the relative importance of different community assembly processes. Ecology. https://doi.org/10.1890/ 14-0454.1.

Valencia R, Foster RB, Villa G, Condit R, Svenning J-C, Hernandez C, Romoleroux K, Losos E, Magard E, Balslev H (2004) Tree species distributions and local habitat variation in the Amazon: large forest plot in eastern Ecuador. J Ecol 92:214-229

Wang Q, Xu Y, Lu Z, Bao D, Guo Y, Lu J, Zhang K, Liu H, Meng H, Qiao X, Huang $H$, Jiang $M$ (2014) Disentangling the effects of topography and space on the distributions of dominant species in a subtropical forest. Chin Sci Bull 59(35): $5113-5122$

Wang XG, Hao ZQ, Ye J, Zhang J, Li BH, Yao XL (2008) Spatial pattern of diversity in an old-growth temperate forest in northeastern China. Acta Oecol 33(3): 345-354

Wang XG, Wiegand T, Hao ZQ, Li BH, Ye J, Lin F (2010) Species associations in an old-growth temperate forest in North-Eastern China. J Ecol 98(3):674-686

Wang Z, Ye W, Cao H, Huang Z, Lian J, Li L, Wei S, Sun IF (2009) Speciestopography association in a species-rich subtropical forest of China. Basic Appl Ecol 10:648-655

Webb CO, Peart DR (2000) Habitat associations of trees and seedlings in a Bornean rain forest. J Ecol 88(3):464-478
Wiegand T, Gunatilleke S, Gunatilleke N (2007) Species associations in a heterogeneous Sri lankan dipterocarp forest. Am Nat 170(4):E77-E95

Wiegand T, Huth A, Getzin S, Wang X, Hao Z, Gunatilleke CVS, Gunatilleke IAUN (2012) testing the independent species' arrangement assertion made by theories of stochastic geometry of biodiversity. Proc Royal Soc B Biol Sci 279: $3312-3320$

Wiegand T, Moloney KA (2004) Rings, circles, and null-models for point pattern analysis in ecology. Oikos 104(2):209-229

Wright SJ (2002) Plant diversity in tropical forests: a review of mechanisms of species coexistence. Oecologia 130(1):1-14

Yang QS, Shen GC, Liu HM, Wang ZH, Ma ZP, Fang XF, Zhang J, Wang XH (2016) Detangling the effects of environmental filtering and dispersal limitation on aggregated distributions of tree and shrub species: life stage matters. PLoS One 11(5):e0156326

Yu XD, Lü L, Wang FY, Luo TH, Zou SS, Wang CB, Song TT, Zhou HZ (2016) The relative importance of spatial and local environmental factors in determining beetle assemblages in the inner Mongolia grassland. PLoS One 11(5): e0154659

Zhang CY, Zhao YH, Zhao XH, Gadow KV (2012) Species-habitat associations in a northern temperate forest in China. Silva Fenn 46(4):501-519

Zhang ZH, Hu G, Zhu JD, Ni J (2013) Aggregated spatial distributions of species in a subtropical karst forest, southwestern China. J Plant Ecol 6(2):131-140

\section{Publisher's Note}

Springer Nature remains neutral with regard to jurisdictional claims in published maps and institutional affiliations.

\section{Submit your manuscript to a SpringerOpen ${ }^{\circ}$ journal and benefit from:}

- Convenient online submission

- Rigorous peer review

- Open access: articles freely available online

- High visibility within the field

- Retaining the copyright to your article

Submit your next manuscript at $\boldsymbol{\nabla}$ springeropen.com 